\title{
Relation between Strength of Blended Yarns of Polyester Fibers and Component Fibers at Breaking Point
}

By Seiichiro Ueno, Member, TMS

\author{
Faculty of Engineering, Gunma University, Kiryu
}

\begin{abstract}
With blended yarns of polyester fibers. "Tetoron", as an example, an attempt has been made to measure the ratio of the component fibers at both ends of yarn breaking point and to survey the relation between (a) blend percentage, (b) thickness measured by counting the number of the component fibers and (c) the actual yarn strength. The attempt was made by recording the breaking strength of blended yarns and counting the component fibers at the point of yarn breaking point in a strength test. The results obtained are:

(1) The number of component fibers and the blend percentage of "Tetoron" on one side of the yarn breaking point do not differ significantly from that on the other side.

Besides, the ratio, calculated by sampling, of the mean number of fibers at the point of yarn breaking point to the respective mean numbers of fibers in cut sections helps greatly in determining the percentage of breaking point and withdrawal of fibers in blended yarns. The larger this ratio, the higher the actual breaking length of blended yarns.

(2) An examination of the relation of the actual strength to the thickness and blend percentage of "Tetoron" has shown that strength has a correlation to thickness but not necessarily to the blend percentages. Strength is presumably influenced by the distribution of fibers in yarn sections.
\end{abstract}

\section{Introduction}

The factors influencing the strength of a blended yarn include the fibers constituting the yarn, blend irregularity, as well as fibers arrangement, entanglement, twist and the number of fibers.

The influence of the distribution of component fibers on yarn strength has been surveyed with blended yarns of polyester fibers "Tetoron", as examples.

The survey included investigating the relation between the strength of the blended yarns and the blend percentage and ccunting the number of the component fibers at the yarn breaking point.

It included als ${ }^{n}$ statistical inquiry, from a correlation point of view, into yarn strength, with attention paid to blend irregularity (the state of the distribution of the component fibers). Hitherto yarn strength has usually been expressed in its relation to a nominal or mean blend percentage.

Factors other than blend irregularity are excluded from discussion in the present article.

\section{Test Samples and Method of Experiments}

The sample "Tetoron" blended yarns used in our experiments are listed in Table 1.

Table 1 Test Samples

\begin{tabular}{lcccc}
\hline Name & Blend & $(\%)$ & Count(s) & $\begin{array}{c}\text { Denier, } \\
\text { Cut }(\mathrm{d} \times \mathrm{mm})\end{array}$ \\
\hline$T R A$ & "Tetoron"/Rayon & $55 / 45$ & 40 & $2 \times 51 / 2 \times 51$ \\
$T R B$ & " & $65 / 35$ & $40 / 2$ & $2 \times 51 / 2 \times 51$ \\
$T R C$ & " & $55 / 45$ & 30 & $2 \times 64 / 3 \times 64$ \\
$T R D$ & " & $65 / 35$ & 16 & $2 \times 51 / 2 \times 51$ \\
$T C$ & "Tetoron", Cotton & $65 / 35$ & $67 / 2$ & $1.5 \times 38 / 1.7 \times 39$
\end{tabular}

The strength of the samples was measured with a yarn strength tester of the Schopper type (tensile speed $30 \mathrm{~cm} / \mathrm{min}$.) 50 times continuously with samples $20 \mathrm{~cm}$ long on the tester. The breaking strength of each sample was recorded. Each side of the yarn breaking point was cut $1.5 \mathrm{~mm}$ long from the end and the number of the component fibers on each 
side counted by spreading them under a microscope. (The cut length for counting the number of fibers at the breaking point should not be too long or too short. In our experiments, we made it $1.5 \mathrm{~mm}$.)

We counted the number of fibers on both sides of the breaking point because yarn breaking point is presumably caused by both fiber breaking point and fiber withdrawal, so that counting the number only on one side might have resulted in our getting an inexact value.

The blended yarns used in our experiments were pre-dyed so that the component fibers at the breaking point could be distinguished. (Rayon and cotton were dyed in a solution of $1 \%$ Direct Blue $2 \mathrm{BN}$ and $3 \% \mathrm{BaSO}_{4}$, at $90-110^{\circ} \mathrm{C}$ for $15-20$ minutes, then washed and dried.) Then a strength test was made. Some difference was observable between pre-dyeing strength and post-dyeing strength (due to a change in the number of twists, etc. during the dyeing process). Accordingly, the data of strength presented in this article concern post-dyeing strength exclusively.

\section{Results of Experiments and Discussions}

\section{2-1 Number of Component Fibers at Yarn Breaking Point}

As we have said, counting the number of fibers only on one side of the breaking point is insufficient for inquiry into the relation between the number of component fibers and breaking strength. We did the counting on both sides, with the results shown in Table 2.

The difference between the number of component fibers on the upper side of the breaking point and the number on the lower side was tested statistically[1] from the values given in Table 2 . There were differences in the number of fibers frnm one individual section to another, but there were no significant differences in the mean number of the component fibers of any of the samples, if the individual sections were taken as a combined whole.

The relation between the number of component fibers on the upper side of the breaking point and the number on the lower side in each section was investigated. For example, if there were relatively many "Tetoron" fibers on one side of the breaking point, were there as more or fewer on the cther? If there was a large aggregate number of fibers on one side, how about the aggregate number on the other side? The questions were resolved in
Table 2 Mean Number $(\bar{T}, \bar{R}, \bar{t})$ and Coefficient of Variations $(\mathrm{CV} \%)$ of Component Fibers

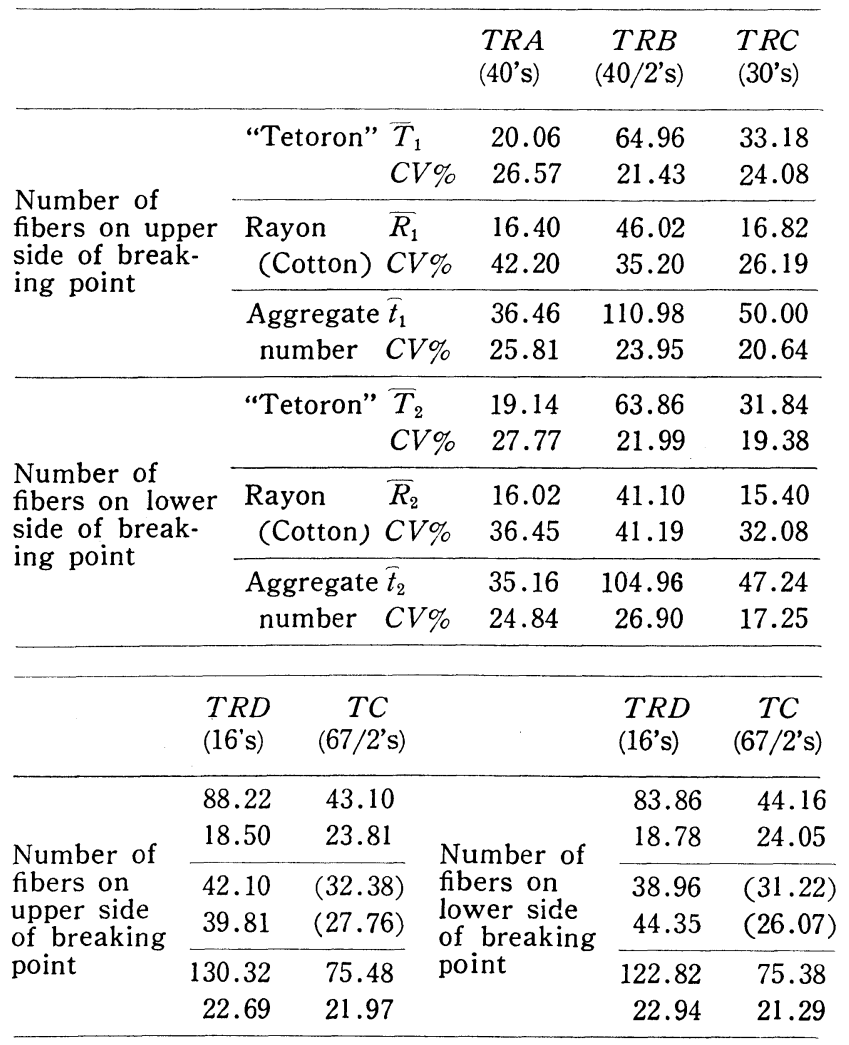

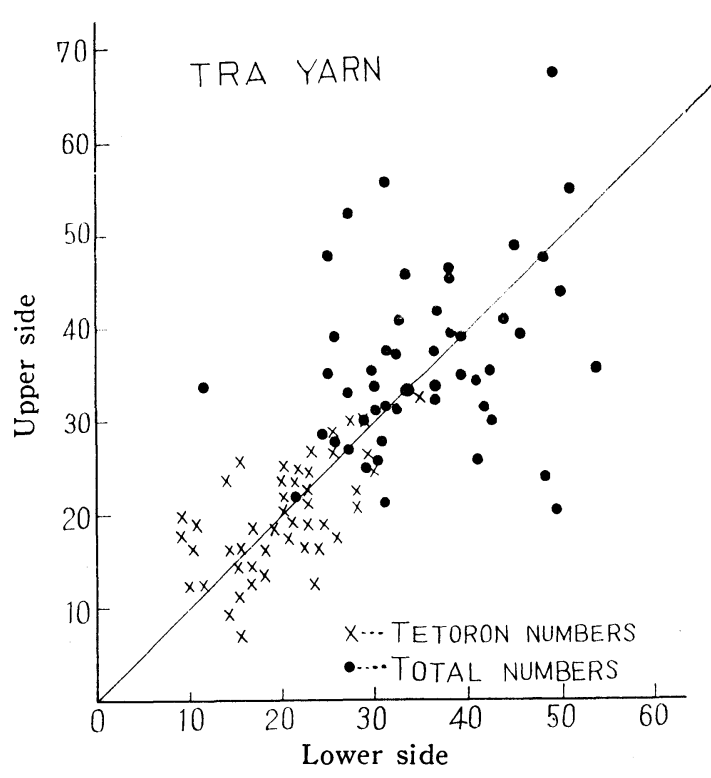

- Total numbers $\quad \times$ Tetoron numbers

Fig. 1(a) Relation between number of fibers on upper side and number on lower side of breaking roint in TRA yarn 


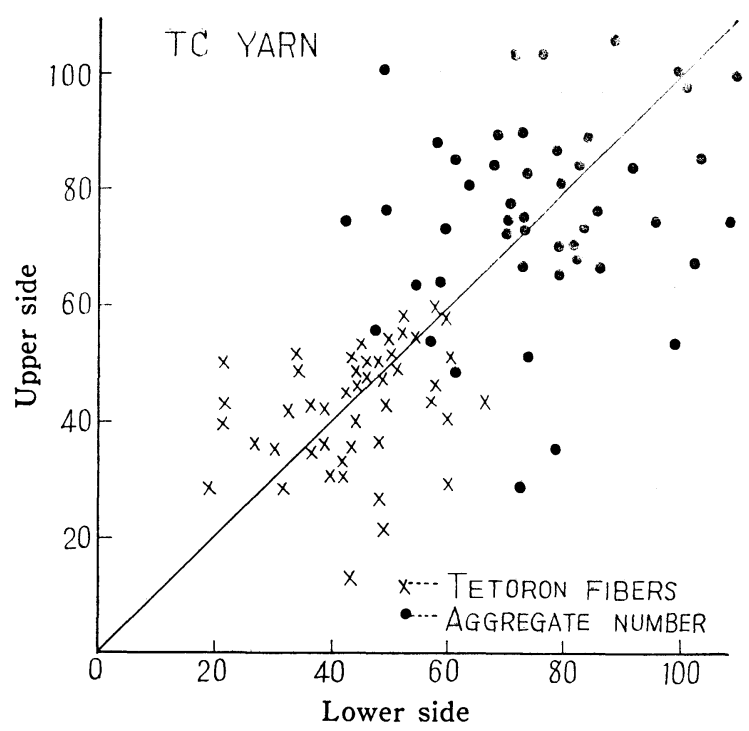

- Aggregate number $\times$ Tetoron numbers

Fig. 1(b) Relation between number of fibc rs on upper side and number on lower side of breaking point in $T C$ yarn

Table 3 Coefficients of Correlation $r$

\begin{tabular}{llllll}
\hline & $T R A$ & $T R B$ & $T R C$ & $T R D$ & $T C$ \\
\hline $\begin{array}{c}\text { Number of } \\
\text { "Tetoron" fibers }\end{array}$ & $0.624^{* *}$ & $0.444^{* * * *}$ & $0.514^{* *}$ & $0.546^{* *}$ & 0.239 \\
$\begin{array}{c}\text { Aggregate number } \\
\text { of fibers }\end{array}$ & $0.397^{* *}$ & 0.245 & $0.355^{*}$ & $0.346^{*}$ & 0.188 \\
\hline
\end{tabular}

(Note 1) $\quad r$ in 0.05 significance level $=0.278$

Mark * : significant at 0.05 level

$r$ in 0.01 significance level $=0.359$

Mark **: significant at 0.01 level

terms of the coefficient of correlation. Some parts of them are drawn in Figure 1 and the coefficients of correlation are shown in Table 3 .

We see, from Table 3, that the number of "Tetoron" fibers, except those constituting TC yarn, distribute fairly evenly on both sides of the breaking point, instead of concentrating on one side.

A similar relation is noticed in the aggregate number of fibers. However, the coefficients of correlation on the aggregate number of fibers are generally lower than those on the number of "Tetoron" fibers, because rayon fibers do not distribute on both sides of the breaking point as uniformly as "Tetoron" fibers do. Details on TC yarn will be given later.

The data on the blend percentage at the point of yarn breaking point are given in Table 4 .
This table shows that the actual blend percentage on either sides of the breaking point does not differ significantly from nominal[1]. In other words, these yarns show nominal blend percentages on both sides of the breaking point. Further, the relation between the blend percentage on the upper and lower sides of the breaking point in each section generally show a significant positive correlation.

All this shows that, statistically speaking, fibers of any one kind, except in a few blended yarns, do not concentrate heavily on one side of the yarn breaking point.

As shown in Tables 3 and 4 , cotton in TC blended yarn dnes not exhibit a correlation between the number of fibers on the upper side of the breaking point and the number on the lower in individual sections but does exhibit a significant correlation between the blend percentage on the upper side and the percentage on the lower side of the breaking point in individual sections. This is presumably because yarn breaking point induces more fiber withdrawals in some sections and more fiber breaking point in other sections. In other words, it seems that larger twist irregularity and larger variations in the breaking strength result from yarn breaking point. (As shown in Table 6, the coefficient of variations in the breaking strength for $T C$ yarn seems larger than that for the other yarns.)

However, the significant correlation between the blend percentage on the upper and lower sides is explained by the fact that the ratios of component fibers on either side does not differ much even if, in case of fiber withdrawa!, there are more fibers on one or the other side.

Further, as shown in Table 3, the correlation between the blend percentage on the upper and

Table 4 Blend Percentage (for "Tetoron") $\bar{W} \%$

\begin{tabular}{|c|c|c|c|c|c|c|}
\hline & & $T R A$ & $T R B$ & $T R C$ & $T R D$ & $\pi C$ \\
\hline Upper & $\bar{W}_{1} \%$ & 55.02 & 58.53 & 56.83 & 67.77 & 54.08 \\
\hline part & $V($ Variance $)$ & 148.20 & 51.57 & 83.69 & 52.02 & 43.49 \\
\hline Lower & $\bar{W}_{2} \%$ & 54.44 & 60.84 & 57.95 & 68.28 & 55.53 \\
\hline part & $V($ Variance $)$ & 139.33 & 55.75 & 96.46 & 56.22 & 52.56 \\
\hline \multicolumn{2}{|c|}{ (c.f.) Norminal } & $55 \%$ & $65 \%$ & $55 \%$ & $65 \%$ & $65 \%$ \\
\hline
\end{tabular}

Coefficients of correlation

between upper

and lower sides 
lower sides is not significant in $T R B$ or $T R D$ yarns, while a significant correlation is found between the numbers of fibers in "Tetoron" on the two sides. This means that rayon withdrawal concentrates on one or the side in case of fiber withdrawal; and that, therefore, the correlations between the aggregate number of fibers are smaller than those between the numbers of "Tetoron" fibers (Table 3). (An investigation of the distribution of the numbers of the component fibers in the yarn sections showed that blended yarn of $65 \%$ "Tetoron" and $35 \%$ rayon was apt to form more clusters than blended yarn of $55 \%$ and $45 \%$.[4])

To sum up, when the numbers of fibers and the blend percentages at the breaking point of "Tetoron"rayon blended yarn are respectively considered in relation with the strength, it is sufficient, from a statistical point of view, to count the number of fi sers only on one side of the breaking point, although this may not apply to some samples.

2-2. Relation between the Number of Fibers at Yarn Breaking Point and the Numbers in Cut Sections

The data on component fibers in 50 sections of each of several blended yarns measured at sampling intervals of $10 \mathrm{~cm}$ [2] are shown in Table 5 .

Table 5 Mean Numbers $(\bar{T}, \bar{R}, \bar{t})$ of Component Fibers and Coefficients of Their Variations $(C V \%)$

\begin{tabular}{clrrrrr}
\hline & & $T R A$ & $T R B$ & TRC & TRD & TC \\
\hline "Tetoron" & $\bar{T}$ & 53.04 & 90.68 & 56.56 & 114.18 & 77.90 \\
& $C V \%$ & 18.29 & 11.68 & 16.46 & 15.34 & 12.94 \\
Rayon & $\bar{K}$ & 39.96 & 57.14 & 30.72 & 52.14 & $(30.90)$ \\
(Cotton) & $C V \%$ & 19.82 & 18.62 & 24.74 & 18.78 & $(19.65)$ \\
\hline Aggregate & $\bar{t}$ & 93.00 & 147.82 & 87.28 & 166.32 & 108.80 \\
number & $C V \%$ & 13.16 & 11.73 & 14.12 & 14.04 & 9.57 \\
\hline
\end{tabular}

How do the numbers of fibers in cut sections of the yarns listed in Table 5 distribute on both sides of the breaking point upon yarn breaking point? The answer is obtainable by comparing the ratios of the numbers of fibers in Table 2 to the ratios of the numbers of fibers in Table 5 . This was done with the results given in Fig. 2 (The figures drawn are the ratios of the mean numbers of fibers).

Assume that the fibers in the cut sections are arranged abreast and that they all break down. Then the respective numbers of the component fibers on both sides of the breaking point theoretically equal the numbers of fibers in the cut sections. Assuming the withdrawal of all the fibers on both sides of the breaking point, then their numbers are theoretically equal to the respective numbers of fibers in the cut sections.

It seems, therefore, that the higher the ratios, given in Fig. 2, of the numbers of fibers on both sides of the breaking point, the larger the number of broken fibers, rather than the numbers of fibers withdrawn. The closer the ratio of the aggregate

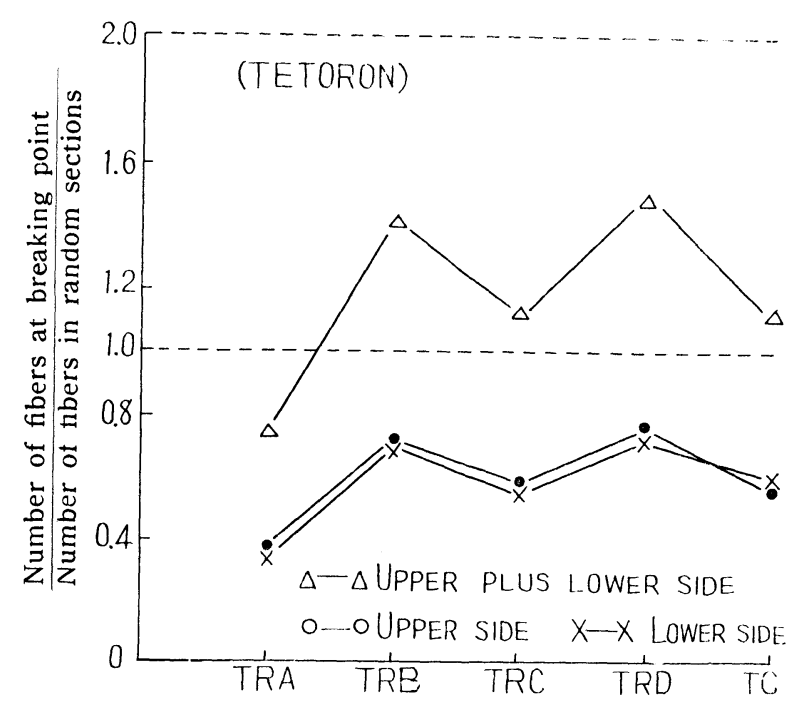

Fig. 2(a) Ratio of number of tetoron fibers at breaking point to numbers in cut sections

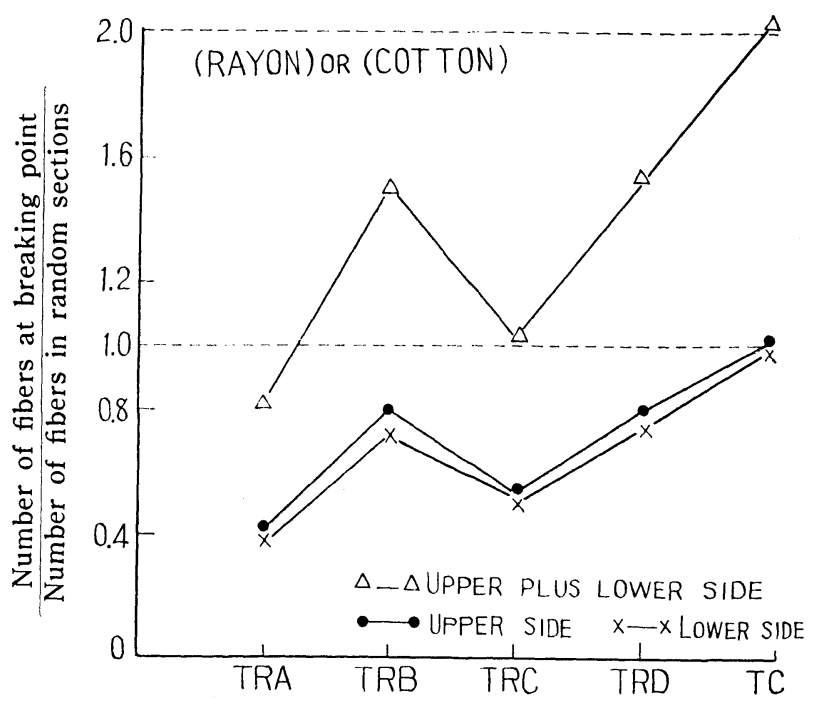

Fig. 2(b) Ratio of number of rayon fibers (or cotton) at breaking point to numbers in cut section 


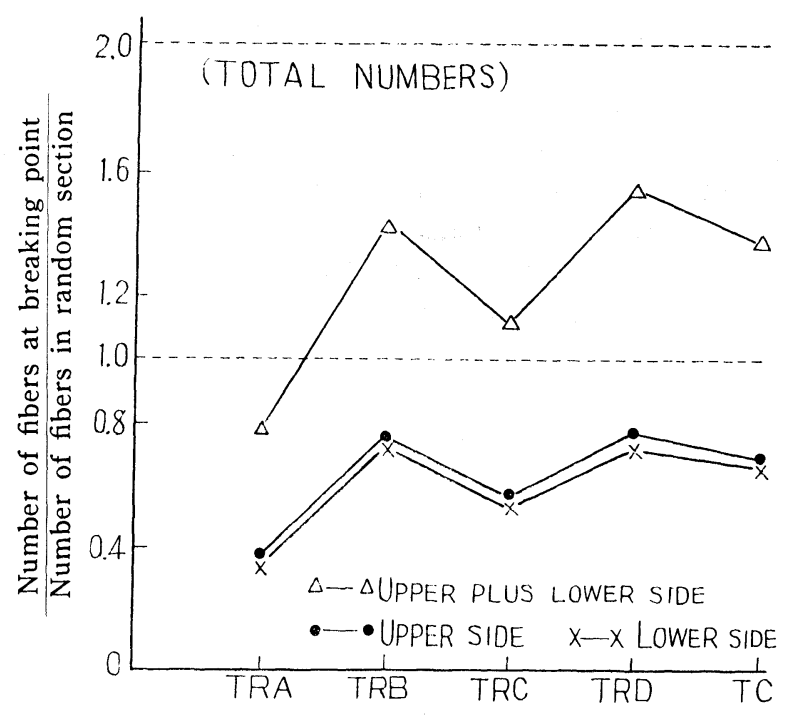

Fig. 2(c) Ratio of aggregate number at breaking point to numbers in cut sections

number of fibers on the upper and lower sides is to 1 , it seems, the larger the number of fibers withrawn. The closer this ratio is to 2 , the larger the number of broken fibers, it seems.

Fig. 2 shows that the value of cotton only in $T C$ yarn is very high. This is presumably because the breaking point contains short (floating) fibers in large numbers and, consequently, more broken fibers turn up there-rather than because broken fibers have a way of concentrating at the breaking point.

It appears also that the percentage of broken fibers is higher in $T R B, T R D$ and $T C$ yarns than in $T R A$ and $T R C$. This coincides with the tendency of the total breaking strength calculated on the basis of strength and shown in Table 6 .

Table 6 Breaking Strength, Calculated Count and Breaking Length

\begin{tabular}{lccccc} 
& TRA & TRB & TRC & TRD & TC \\
\hline $\begin{array}{l}\text { Break- Mean } \\
\text { ing }\end{array}$ & $\begin{array}{l}\text { Value } \bar{P}(\mathrm{~g}) \\
\begin{array}{c}\text { Coefficient of } \\
\text { 180.74 }\end{array}\end{array}$ & 453.81 & 273.07 & 547.22 & 281.14 \\
$\begin{array}{c}\text { Strength variation } \\
\text { CV\% }\end{array}$ & 11.98 & 10.96 & 9.35 & 12.99 & 13.25 \\
$\begin{array}{c}\text { Calculated count (s) } \\
\text { Breaking length } \\
\mathrm{R}(\mathrm{km})\end{array}$ & 28.58 & $35.96 / 2$ & 25.89 & 15.98 & $62.76 / 2$ \\
\hline
\end{tabular}

(Note 2) Breaking length $R=\frac{P \times N \times L}{G}$

where $N$ : Count, $P$ : Yarn strength $(\mathrm{g})$

$L$ : Standard length $(\mathrm{m})$,

$G$ : Standard weight $(\mathrm{g})$

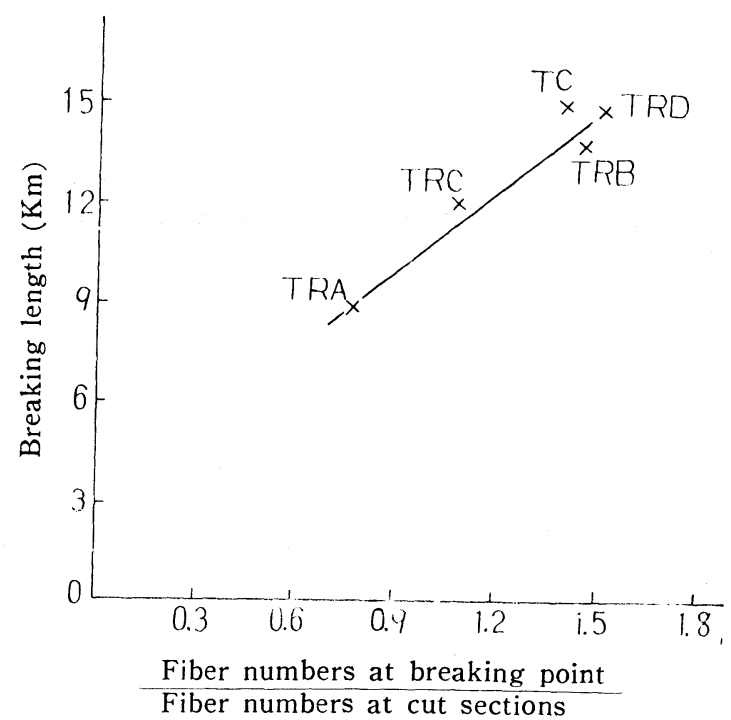

Fig. 3 Relation between breaking length and ratio of number of fibers at breaking point to numbers in cut sections

The linear relation shown in Fig. 3 indicates that the higher the ratio of the number of fibers at the yarn breaking point is to the numbers of fibers in cut sections-i.e., the higher the percentage of broken fibers-the longer the breaking length. (Theoretically, the relation just mentioned should not fall below 1. Since, however, the same sample cannot be measured both at the breaking point and in cut sections, the value (below 1) shown in Fig. 2 for $T R A$ turns up in consequence of yarn irregularity.) We may say, then, that $65 / 35$ blended yarn is stronger than $55 / 45$.

The counts calculated from the actual numbers of the fibers are used for $N$. Measuring the breaking length is due to the reason that should like to compare the strength by correcting to identical measure because any counts in each blended yarn differ severally.

We compare the values at the yarn breaking point with those in cut sections by sampling (see Table 7) for mean blend percentages and variances of the samples of various kinds.

Table 7 Blend Percentages (for "Tetoron") $\bar{W} \%$

\begin{tabular}{lccccc} 
& TRA & TRB & TRC & 1RD & TC \\
\hline $\bar{W} \%$ & 57.03 & 61.34 & 55.15 & 68.65 & 58.34 \\
$V$ (Variance) & 20.00 & 17.97 & 48.22 & 15.86 & 44.02 \\
\hline
\end{tabular}


The mean blend percentages at the yarn breaking point (Tables 7 and 4) do not differ significantly[1], but their variances (blend irregularity) do. The tables clearly show that the degree of blend irregularities calculated from the respective numbers of fibers in sampled cut sections are much smaller than those at the yarn breaking point. (Only in TC yarn is this difference not noticed and blend irregularity at the breaking point is also comparatively small.)

This means that the weak point (the breaking point) of a blended yarn is not limited to a specific part of a blend percentage but arises out of its relation to yarn thickness. In other words, it seems as if there is only a slight relation of positive correlation between blend percentage and yarn thickness. In TC yarn, however, there may conceivably be some definite relation between them, for the reason we have just given.

2-3 Relation between Actual Strength, Blend Percentage and Yarn Thickness

Here, yarn thickness is a value calculated by amending the volume of another fiber by using "Tetoron", as a basis.

Assume that:

$T$ : The number of component fibers of "Tetoron".

$R(C)$ : The number of component fibers of rayon (cotton).

$d_{T} \quad$ : Denier of "Tetoron".

$d_{R(C)}:$ Denier of rayon (cotton)

$\rho_{T} \quad$ : Specific gravity of "Tetoron".

$\rho_{R(0)}$ : Specific gravity of rayon (cotton)

Then, the thickness of rayon needs an amendment of volume by $R \times \frac{d_{R}}{d_{T}} \times \frac{\rho_{T}}{\rho_{R}}$, based on "Tetoron". Ralative thickness $F$, in this case is, therefore:

$$
F=T+R \times \frac{d_{R}}{d_{T}} \times \frac{\rho_{T}}{\rho_{R}}
$$

Thus, $F$ calculated by this equation is taken as yarn thickness.

Assume that:

$P$ : Actual strength. $\quad F$ : Thickness.

$W$ : Blend percentage in "Tetoron".

To find out what correlation there is among these three variables, we have only to exclude the effect of one of them and find out the relation between the other two, i.e., to calculate the coefficient of partial correlation.[3] The value of the coefficient of correlation is obtainable from this equation:

$$
\begin{aligned}
& r_{F P \cdot W}=\frac{r_{H^{\prime}}-r_{W F} \cdot r_{P W}}{\sqrt{\left(1-r_{W H}^{2}\right)\left(1-r^{2}{ }_{P W}\right)}} \\
& r_{P W \cdot F}=\frac{r_{P W}-r_{F P} \cdot r_{W F}}{\sqrt{\left(1-r^{2}{ }_{F P}\right)\left(1-r_{W F}^{2}\right)}}
\end{aligned}
$$

(c.f.)

$$
r_{W F \cdot P}=\frac{r_{W F}-r_{P W} \cdot r_{F^{\prime} P}}{\sqrt{\left.1-r_{P W}^{2}\right)\left(1-r_{F P}^{2}\right)}}
$$

The suffix $r$ denotes the relation between the two terms on the left of the dot when the term lying on the right is stationary. Eqs. (1) and (2) express the relation between the actual strength and the thickness (except the effect of the blend percentage) and the relation between the actual strength and the blend percentage (except the effect of the thickness). The expressions given as blend percentages and thicknesses are those only on the upper side of the point of the yarn breaking point. As we have already said, there is generally a positive correlation between the numbers of fibers on the upper lower sides.

To test the coefficient of partial correlation, use $t$ test as is done to test the coefficient of single correlation. However, the degree of freedom in this case is $(n-3)$. That is to say, this test is done by using the following equation (4):

$$
t_{0}=\frac{r \sqrt{n-3}}{\sqrt{1-r^{2}}}
$$

(Note 3) Calculating the value of $r$ by substituting $t_{47}(0.05)=2.014, t_{47}(0.01)=2.689$ into eq. (4) gives us $r$ in $5 \%$ significance level $= \pm 0.282$ and $r$ in $1 \%$ significance level $= \pm 0.376$. Marks* and** in Table 8 express the values judged significant at $5 \%$ and $1 \%$ levels.

Similarly, it is possible to test the significant difference between the coefficient of single correlation and the coefficient of partial correlation within the same limit as in Table 8[3].

Table 8 Coefficients of Single Correlation and Coefficients of Partial Correlation

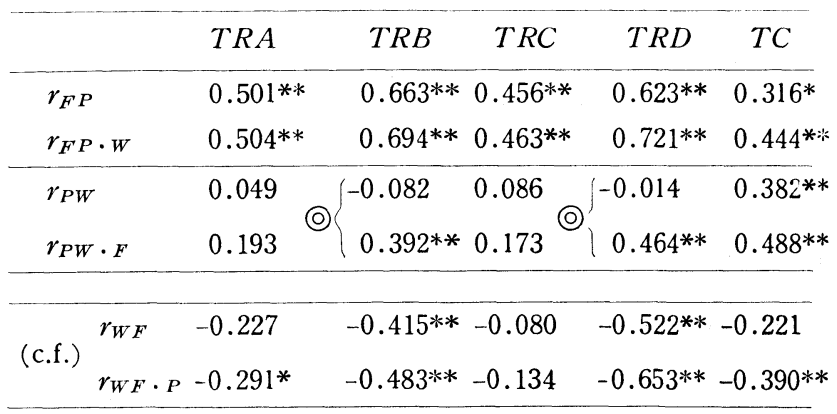


(Note 4) In equation $u=\frac{Z r_{1}-Z r_{2}}{\sqrt{\frac{1}{n_{1}-3}+\frac{1}{n_{2}-3}}}$

put $n_{1}=n_{2}=50, \quad u_{0.05}=1.960, \quad u_{0.01}=2.576$. Then, the limit values of the significant differences for the coefficient of correlation are $Z r_{1}-Z r_{2}=0.404$ at a $5 \%$ level and $Z r_{1}-Z r_{2}=0.531$ at a $1 \%$ level, where $Z r_{1}$ and $Z r_{3}$ are the values obtained by $Z$ transformation. Mark (?) in Table 8 expresses the value judged significant at a $5 \%$ level.

Table 8 shows that the relation between two variables, if not made clear only by calculating the coefficient of single correlation, is made clear by calculating the coefficient of partial correlation. For example, when the values of both the coefficients of single and partial correlation are close to each other, like $r_{F^{P}}$ and $r_{F^{P} \cdot W}$, fixed variable $W$ has no important effect upon strength. When there is a significant difference between the two coefficients in some samples, as between $r_{P W}$ and $r_{P W \cdot F}$, fixed variable $F$ may affect strength.

All this goes to show that there is a relation of positive correlation between the actual strength and the thickness of any blended yarn; and that the coarser the yarn, the higher its actual strength. (see Fig. 4)

The relation between the percentage of "Tetoron", strength and thickness varies from sample to sample. In $T R A$ or $T R C$, the blend percentage shows no relation to actual strength and hardly any to thickness, either.

In $T R B$ and $T R D$ yarns, the blend percentage has a bearing on actual strength; the higher the percentage of "Tetoron", the higher the actual strength, tends to be (see partial correlation), but thickness has a negative effect on the blend percentage. In TC yarn, the blend percentage shows a positive correlation to strength (see partial correlation), but thickness shows hardly any correlation to strength.

Why these variation, from sample to sample, in the relation between the percentage of "Tetoron" and strength? For one reason, TRA and TRC yarns contain $55 \%$ "Tetoron"; TRB, TRD and TC yarns, $65 \%$. The percentage of "Tetoron" seems to influence strength considerably.

The negative correlation between the blend percentage and thickness of $T R B$ and TRD seems adequate, because the variations in the number of rayon fibers in these yarns exceed the variations in the number of "Tetoron" fibers. Also these two yarns are relatively coarser than the other three.

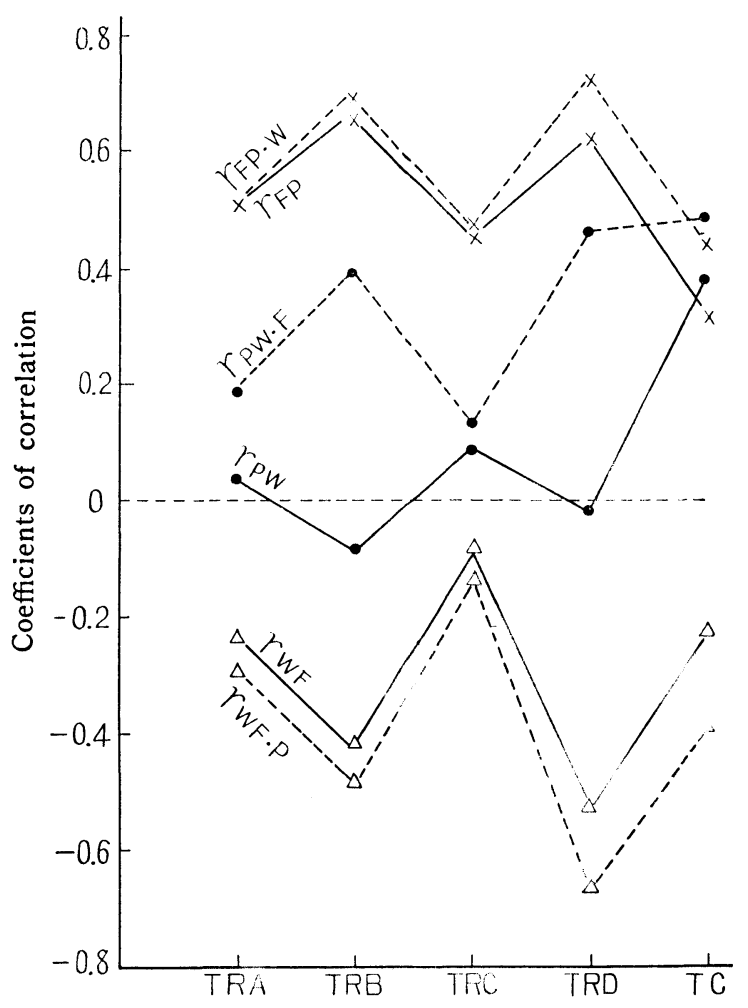

Fig. 4 Comparing coefficients of partial correlation and those of single correlation

\section{Conclusions}

It is a difficult task to fix the proper cut length from the end of yarn breaking point preparatory to counting the component fibers at the breaking point during a strength test of a blended yarn. If the cut length is too short, it includes fibers unrelated to breaking point. If it is too short, it omits fibers related to breaking point. The author, in his experiments, made the cut length $1.5 \mathrm{~mm}$. The results of the experiments on blended yarns of polyester fibers ("Tetoron") are:

(1) Generally, there is a positive correlation between the numbers of component fibers on both sides of the breaking point, on the one hand, and the percentage of "Tetoron", on the other. There is $\mathrm{n}$ ) significant difference between the mean number of fibers and the blend percentage on one side of the breaking point and those on the other side. Accordingly, if we consider the mean number of fibers and the blend percentage in their relation to breaking strength, it is enough to count the number of fibers only on one side of the breaking point. 
(2) Connting the ratio of the mean number of fibers at the point of yarn breaking point to the respective mean numbers of fibers in sampled cut sections helps greatly to determine the percentage of breaking point and of withdrawal of fibers in a blended yarn. The larger this ratio (maximum value calculated is 1 ), i.e. the higher the percentage of fiber breaking point, the higher the actual breaking length. (In fact, a yarn of $65 \%$ "Tetoron" and $35 \%$ rayon shows higher strength.)

(3) An examination of the relation between actual strength, thickness and blend percentage has shown that strength has a correlation with the thickness of any blended yarn, if we exclude the effects of the other variables. The coarser a yarn, the higher its strength; but the blend percentage does not necessarily have a bearing on strength. However, blended yarn having a high "Tetoron" content (e.g., $65 \%$ "Tetoron" $/ 35 \%$ rayon), the percentages of "Tetoron" has considerable influence on strength. This is because each kind of component fiber is apt to form clusters in yarn sections if the percentage of one kind of component is higher[4].

Besides, the negative correlation between the percentage of "Tetoron" and the thickness of a yarn means that the percentages of rayon (or cotton) is comparatively high in the coarser areas of the yarn. This is related to the fact that the irregularity degree of the cotton (or rayon) fibers in a yarn is higher than that of "Tetoron".

(4) A "Tetoron"-cotton blended yarn gives results different in many ways from those obtained from a "Tetoron"-rayon blended yarn

The author thanks Teijin Ltd. for the samples furnished him. Acknowledgements are due also to T. Motegi and T. Ushigome for their constant cooperation in our experiments.

\section{References}

[1] Research Society of Statistical Engineering, Tokyo Institute of Technology: "Handbook of Statistical Engineering" (1953)

[2] S. Ueno and T. Motegi: Research Publication in Text. Soc., Japan (1961-10)

[3] S. Mizuno: Textbook of Statistical Training Course by Chem. Soc., Japan (1952)

[4] S. Ueno: J. Text. Soc., Japan, Japanese ed., 17, 614, $621(1961-7)$ 